\title{
Present scenario of generic medicines in India: A comparative study
}

\author{
Tapan Kumar Mahato ${ }^{1, *}$ and Durgeshwari Raulji 2 \\ ${ }^{1}$ Department of Pharmaceutical Analysis, B.Pharmacy College Rampura, Post office Kakanpur, Taluka Godhra, District \\ Panchmahal, Gujarat, India. \\ ${ }^{2}$ B. Pharmacy College Rampura, Post office Kakanpur, Taluka Godhra, District Panchmahal, Gujarat, India.
}

World Journal of Biology Pharmacy and Health Sciences, 2021, 07(02), 053-059

Publication history: Received on 10 July 2021; revised on 14 August 2021; accepted on 16 August 2021

Article DOI: https://doi.org/10.30574/wjbphs.2021.7.2.0086

\begin{abstract}
Drugs or medicines are those which are used for treatment, diagnosis, mitigation and prevention of diseases. But it's very expensive. Not or all but for lower and middle class people taking treatment is very difficult because of the cost of the medicines. Many deaths are caused because the patient cannot afford the cost of the medicines. The entry of generic medicines in market brought a revolutionary change in healthcare system and the market share is continuously increasing. The poor and needy sections of the society are getting benefitted because these are authentic, reliable, secure, affordable and accessible for all. Now there is an option available against the high cost branded medicines. Government of India is taking lot of steps to promote the availability of generic medicines both in rural and urban areas and also taking steps to aware people that it is equally safe and effective as that of branded medicines. Many pharmaceutical companies are manufacturing generic medicines and making them available in market through retail outlets. E-pharmacies are also functioning delivering generic medicines at home. Government has opened thousands of Pradhan Mantri Bhartiya Janaushadhi Kendra (PMBJK) across the country where one can get generic medicines at much lower cost. The present article is based on the study to know the availability of generic medicines through PMBJK, comparison of prices between generic and branded medicines, reasons for the lower price of generic medicines and except PMBJK where generic medicines are available.
\end{abstract}

Keywords: Generic medicines; Pradhan Mantri Bhartiya Janaushadhi Pariyojna PMBJP; Pradhan Mantri Bhartiya Janaushadhi Kendra PMBJK; Price comparison of generic and branded medicines; Market share of generic medicines in India

\section{Introduction}

According to the definition given by the World Health Organization (WHO), generic medicines or generics are pharmaceutical products usually intended to be interchangeable with the innovator product, marketed when period of patent is over or other exclusivity rights [1]. Generic medicines are like boon among people who usually tends to ignore the hazardous implications on their health, just because of the high cost of the branded medicines. That is why it is contributing in improving the healthcare system of the country. People of India feel difficulty in choosing between branded and non-branded products. On the other hand, in western countries there is no confusion between these two because the concept of generic medicines is very well established. United States filled about 89\% of all the prescriptions with generic medicines and as far as India is concerned, it is in emerging phase [2]. Generic or branded medicines are not clearly defined under the Drugs \& Cosmetics Act, 1940 and Rules, 1945. However, generic medicines are those which contain same active ingredient(s) with same amount in same dosage form, administered by the same route of administration and equivalent safety and efficacy as that of branded medicines [3]. The entry and progress of generics

*Corresponding author: Tapan Kumar Mahato; E-mail: tapan.mahato@gmail.com

2/30, Gandhi nagar, Ratanpur, District Biaspur, Chhattisgarh, India.

Copyright (c) 2021 Author(s) retain the copyright of this article. This article is published under the terms of the Creative Commons Attribution Liscense 4.0. 
into the market is positive sign for patients especially poor and needy, medical organizations, governments (States/Union territories) and negative for manufacturers of branded medicines [1].

\section{Quality of Generic medicines [3]}

Generic or branded drugs which are manufactured in the country are required to comply with the same standards as prescribed in the Drugs and Cosmetics Act, 1940 and Rules, 1945 for their quality and efficacy. Both are expected to have similar effects.

\section{The advantages of generic medicines [1]}

- It usually costs $80 \%$ to $85 \%$ less than the price of branded drugs.

- Considered effective and safe as like branded medicines.

- Both generic and branded drugs come under the same governance and adhere to the same quality standards.

- After the expiration of patent period of branded drugs, they comes to public domain i.e. anyone can manufacture their generic versions.

- Because of the less price of generic medicines and rising competition, pharmaceutical companies comes under pressure to reduce the price of their branded versions.

\section{Lower price of Generic medicines [3]}

Here a question arises that if everything is same then why the cost of branded medicines is higher than generic medicines? The price of a generic medicine is generally lower than the price of a corresponding branded medicine because

- The pharmaceutical company does not promote its product, results in saving of money. Keeping a high trade margin for wholesalers and retailers is the incentive given by pharmaceutical company on sale of generic medicines.

- After inventing a new molecule, Pharmaceutical companies goes for patent of the molecule. Getting patent means no any other pharmaceutical company can manufacture that for period of 20 years. They sell that molecule after formulation in higher cost because they have the only right to manufacture it. After completion of 20 years patent expires and the formula goes to public domain i.e. other pharmaceutical companies can manufacture that and if many companies manufactures the same thing automatically the price will fall down.

\section{Price comparison of Generic Vs Branded medicines}

Here are the some examples which clarifies the price difference between generic and brand medicines. For price of generic medicines, products of PMBJAK \& Davaindia were taken which were compared with the popular pharmaceutical companies

Table 1 Generic (PMBJAK \& Davaindia) Vs Branded: Price comparison [4, 6]

\begin{tabular}{|c|c|c|c|c|}
\hline \multirow[t]{3}{*}{ S.NO. } & \multirow[t]{3}{*}{ Product } & \multicolumn{3}{|c|}{ Price/Quantity } \\
\hline & & \multicolumn{2}{|c|}{ Generic } & \multirow[t]{2}{*}{ Branded } \\
\hline & & PMBJK & $\begin{array}{l}\text { DAVA } \\
\text { INDIA }\end{array}$ & \\
\hline \multicolumn{5}{|c|}{ Analgesic/Antipyretic/Muscle Relaxant } \\
\hline 1 & Ibuprofen tablets $400 \mathrm{mg}$ & $4.88 / 15$ & $\mathrm{XXXX}$ & $11.59 / 15(\wedge$ Abbott $)$ \\
\hline 2 & Paracetamol tablets $650 \mathrm{mg}$ & $8.03 / 15$ & $10 / 10$ & 30.91/15 (^Micro labs) \\
\hline 3 & Paracetamol tablets $500 \mathrm{mg}$ & $4.15 / 10$ & $07 / 10$ & $\begin{array}{c}15.04 / 10 \\
\left({ }^{\wedge} \text { Glaxo smithkline }\right)\end{array}$ \\
\hline
\end{tabular}




\begin{tabular}{|c|c|c|c|c|}
\hline \multicolumn{5}{|c|}{ Antiallergic } \\
\hline 4 & Cetrezine $10 \mathrm{mg}$ film coated tablets & $1.84 / 10$ & $\mathrm{XXXX}$ & 18.40/10 (^Lupin) \\
\hline \multicolumn{5}{|c|}{ Anticancer } \\
\hline 5 & Capecitabine tablets $500 \mathrm{mg}$ & $420 / 10$ & $\mathrm{XXXX}$ & $\begin{array}{c}1328.50 / 10 \\
\left({ }^{\wedge} \text { United biotech) }\right.\end{array}$ \\
\hline \multicolumn{5}{|c|}{ Antiinfective } \\
\hline 6 & $\begin{array}{l}\text { Azithromycin } 500 \mathrm{mg} \text { tablets (film } \\
\text { coated) }\end{array}$ & $86.60 / 10$ & $35 / 03$ & $400.00 / 10\left(^{\wedge}\right.$ Zenali $)$ \\
\hline 7 & Clarithromycin 500 mg tablets & $66.23 / 04$ & $\mathrm{XXXX}$ & $310.00 / 04(\wedge$ Johnlee $)$ \\
\hline \multicolumn{5}{|c|}{ Central Nervous System Acting } \\
\hline 8 & Citicoline tablets $500 \mathrm{mg}$ & $169.88 / 10$ & $\mathrm{XXXX}$ & 690.00/10 (^Cybele) \\
\hline \multicolumn{5}{|c|}{ Cardiovascular Acting } \\
\hline 9 & Amlodipine $5 \mathrm{mg}$ tablets & $2.68 / 10$ & 6.00 & $25.88 / 10\left(^{\wedge}\right.$ Lupin $)$ \\
\hline 10 & Enoxaparin 60 mg/ $0.6 \mathrm{ml} \mathrm{inj}$. & $222.89 / 0.6 \mathrm{ml}$ & $\mathrm{XXXX}$ & $580.00 / 0.6 \mathrm{ml}\left({ }^{\wedge}\right.$ Venus $)$ \\
\hline 11 & $\begin{array}{l}\text { Nifedipine prolonged release tablets } 20 \\
\text { mg }\end{array}$ & $7.09 / 10$ & $18 / 10$ & 28.30/10 (^Zydus cadila) \\
\hline 12 & Aspirin tablets $150 \mathrm{mg}$ & $1.90 / 14$ & XXXX & $\begin{array}{c}8.00 / 10 \\
\left({ }^{\wedge} \text { Twilight Mercntiles) }\right.\end{array}$ \\
\hline \multicolumn{5}{|c|}{ Drugs acting on endocrine glands including steroids and immunosuppressants } \\
\hline 13 & $\begin{array}{l}\text { Methylprednisolone sodium succinate inj. } \\
1000 \mathrm{mg} / \text { vial }\end{array}$ & 494.81/Vial & $\mathrm{XXXX}$ & $\begin{array}{c}\text { 1199.00/Vial } \\
\text { (^Strathspey Labs) }\end{array}$ \\
\hline \multicolumn{5}{|l|}{ ENT } \\
\hline 14 & Nepafenac $0.1 \% \mathrm{w} / \mathrm{v}$ eye drop & $45.00 / 05 \mathrm{ml}$ & $\mathrm{XXXX}$ & $320.00 / 05 \mathrm{ml}\left({ }^{\wedge}\right.$ Alcon labs $)$ \\
\hline \multicolumn{5}{|c|}{ Female Reproductive Organs } \\
\hline 15 & Oxytocin inj. IP $5 \mathrm{iu} / \mathrm{ml}$ & $8.19 / 01 \mathrm{ml}$ & $\mathrm{XXXX}$ & $17.00 / 01 \mathrm{ml}\left({ }^{\wedge}\right.$ Intas $)$ \\
\hline \multicolumn{5}{|l|}{ GIT } \\
\hline 16 & Ursodeoxycholic acid tablets IP $300 \mathrm{mg}$ & $114.58 / 10$ & $185 / 10$ & $296.60 / 10$ (^Zuventus) \\
\hline \multicolumn{5}{|c|}{ Respiratory System } \\
\hline 17 & Salbutamol syrup $2 \mathrm{mg} / 5 \mathrm{ml}$ & $8.00 / 100 \mathrm{ml}$ & XXXX & $\begin{array}{c}16.22 / 100 \mathrm{ml} \\
\left({ }^{\wedge} \text { Ikon remedies) }\right.\end{array}$ \\
\hline \multicolumn{5}{|c|}{ Skin (Topical/Local Application) } \\
\hline 18 & Povidone iodine $5 \%$ solution $100 \mathrm{ml}$ & $\begin{array}{l}\text { Solution } \\
16.50 / 100 \mathrm{ml}\end{array}$ & $\begin{array}{l}\text { Ointment } \\
25 / 25 \mathrm{gm}\end{array}$ & $\begin{array}{l}\text { Solution : } 71.68 / 100 \mathrm{ml} \\
\left.\quad{ }^{\wedge} \text { Kinedex }\right) \\
\text { Ointment : 67.00/25 gm } \\
\left({ }^{\wedge} \text { Win medicare }\right)\end{array}$ \\
\hline \multicolumn{5}{|c|}{ Respiratory Tract Drugs Acting On Urogenital Organs } \\
\hline 19 & Sildenafil tablets $100 \mathrm{mg}$ & $9.61 / 04$ & XXXX & $232.00 / 04\left({ }^{\wedge}\right.$ Mankind) \\
\hline \multicolumn{5}{|c|}{ Diabetes } \\
\hline 20 & $\begin{array}{l}\text { Insulin inj. IP } 40 \mathrm{IU} / \mathrm{ml} \text { (Insulin human } \\
\text { recombinant) }\end{array}$ & $\begin{array}{l}66.70 / 10 \mathrm{ml} \\
\text { Vial }\end{array}$ & $\mathrm{XXXX}$ & $147.06 / 10 \mathrm{ml}$ vial \\
\hline
\end{tabular}




\begin{tabular}{|c|l|l|l|c|}
\hline & & & $\left({ }^{\wedge}\right.$ Shreya life sciences) \\
\hline \multicolumn{2}{|l|}{ Vaccine } & & \multicolumn{2}{|l|}{} \\
\hline 21 & Vaccine rabies inj. 2.5 IU & $152.04 / 01 \mathrm{ml}$ & XXXX & $\begin{array}{c}357.76 / 01 \text { power for Inj. } \\
\left({ }^{\wedge} \text { Indian immunologicals) }\right.\end{array}$ \\
\hline
\end{tabular}

\#XXXX: Not available, ${ }^{\wedge}$ Manufacturer

\subsection{Its compulsory to write prescription with Generic names [3]}

According to Clause 1.5 of Indian Medical Council (Professional Conduct, Etiquette and Ethics) Regulations, 2002, every physician should prescribe drugs with

- Generic names should be used in prescription

- Capital letters should be used to write medicines in prescription

- Ensuring rational prescription and use of drug. Additionally, a circular of the Medical Council of India (MCI), dated 21.04.2017 states that all Registered Medical Practitioners (RMPs) have been directed to comply with the above provisions. Disciplinary action against a doctor can be taken by MCI or State Medical Councils for violation of the provision of the aforesaid Regulations. Complaints against the violation of code of ethics for doctors are referred by MCI to the concerned State Medical Councils (where the doctors/medical practitioners are registered) to take necessary actions. And also according to directives of Tele-Medicine Guidelines 2020, notified on 22nd May, 2020, all RMPs must use Generic Names of the drugs in capital letters on the prescription format.

\subsection{Steps taken by Government of India [3]}

To promote and ensure the quality of generic medicines, Ministry of Health \& Family Welfare, Government of India has taken various regulatory measures like

- With proper/generic names only, Licensing Authorities will grant/ renew licenses to manufacture for sale or for distribution of drugs.

- It is now mandatory to grant license for a drug formulation containing single active ingredient in proper name only, as per the amendment in the Drugs and Cosmetics Rules, 1945.

- According to the provision included in the Rules, 1945, submission of the result of bioequivalence study is mandatory along with the application for grant of manufacturing license in the case of certain drugs.

- As per a provision, Drugs Inspectors of Central Government and State Government can perform joint inspection of manufacturing establishment.

\subsection{Increasing market share of generics medicines [1]}

As per the scenario, developed related to economics, with an increase in supply of generic drugs, the price of these drugs will lower i.e. inversely proportional. What is the reason? The reasons behind the increasing market share of generics medicines are -

- Expiration of patents of drugs i.e. drug comes to public domain and any pharmaceutical company can manufacture it leads to increased availability of drugs at low price

- Big percentage of patients who are not covered by health insurance/medical insurance

- Generic drugs / medications are considered as effective and safe as the branded medications because they are approved by the regulatory bodies like FDA

- Increasing price competition

\section{Sale of Generic Drugs in the country}

On comparing with other countries, India has more generic drug-manufacturing facilities after United States approved by Food \& Drug administration (FDA). India has developed a world-class generic drug manufacturing sector with major generics firms such as Cipla, Ranbaxy, Reddy's Laboratories, etc [1]. According to the reports of WHO, about half of the 
population of the world is tolerating the lack of standard health coverage. Nearly more than95 million people standing with poverty and about 800 million people uses their almost household budget on the medicines and medical bills including India. At present, in field of pharmaceutical industry India is at a very important position. It is considered as the largest provider of generic medicines worldwide. By volume it occupies about $20 \%$ share in global supply including supplies of over $50 \%$ of demand for various vaccines worldwide, catering to $40 \%$ of generic demand in United States and $25 \%$ of all medicines in United Kingdom. India produces about 60,000 generic brands for about 60 different therapeutic categories including manufacturing of more than 500 different Active Pharmaceutical Ingredients(APIs). Export of generic drugs is a power of India which empowers the economy of the country. Here the generic medicine industry plays an important role who works on the agenda of offering, authenticity, affordability and accessibility. The customers/patients are offered and provided with the WHO/FDA approved quality medicines and found much struggle to ensure the efficacy of generic drugs as quality of branded medicines. The industry has a vision to aware and educates the general public on the authenticity and benefits of generic medicines. People will become aware of generic medicines only when they know the advantages of these medicines and it is achieved by educating the general public, it's a long term work. Government of India, in order to promote the use of generic medicines initiated the Pradhan Mantri Janaushadhi Kendra (PMJK). Different sections of society are getting benefitted of generic medicines across the country by PMJK by saving on expenses on medicines [1].

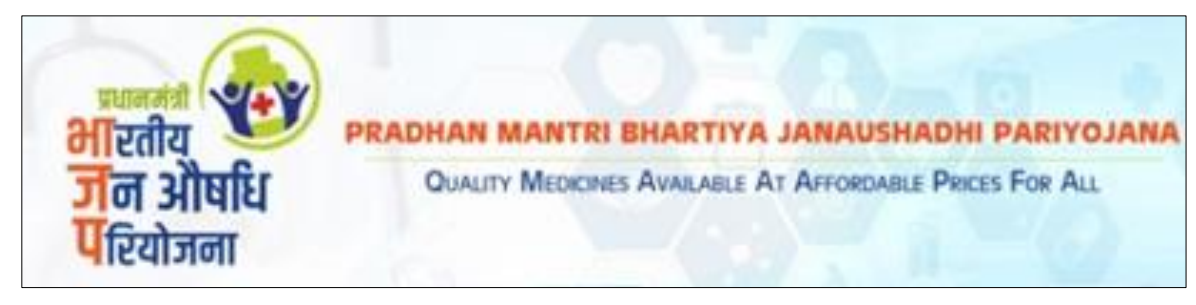

Figure 1 Logo of Pradhan Mantri Bahartiya Janaushadhi Pariyojana (PMBJP), an initiative of Government of India to provide quality and affordable medicines to all

The campaign 'Pradhan Mantri Bhartiya Janaushadhi Pariyojana' (PMBJP)waslaunched in 2008 and again relaunched in 2015 for the noble cause i.e. to provide quality medicines at affordable prices for all (poor/needy people in both rural and urban areas. To achieve the aim Bureau of pharma public sector undertakings of India (BPPI) was established under the Departmentof Pharmaceuticals, Ministry of Chemicals \& Fertilizers, Government of India to sell quality generic medicines across the country through dedicated outlets named as 'Pradhan Mantri Bharitya Janaushadhi Kendra' $(\mathrm{PMBJK})[3]$.

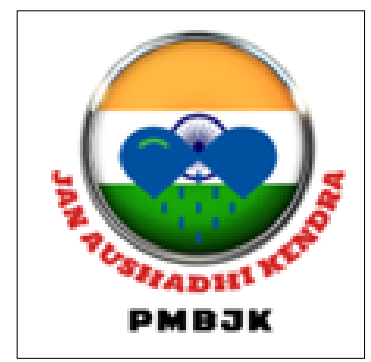

Figure 2 Logo of Pradhan Mantri Bhartiya Janaushadhi Kendra (PMBJK), retail outlets under Pradhan Mantri Bahartiya Janaushadhi Pariyojana (PMBJP) functioning all over India

The categories for which drugs are available are antipyretic \& analgesic/Muscle relaxant, Ant allergic, Anticancer, Antiinfective, Diuretic, Drugs acting on Central nervous system, Drugs acting on Cardiovascular system, Drugs acting on Endocrine glands including steroids \& immunosuppressant, Drugs acting on Eye \& ENT, Drugs acting on Female reproductive organs, Drugs acting on Gastrointestinal tract, Drugs acting on Respiratory tract, Drugs acting on Skin (Topical/Local application),Drugs acting on Urogenital organs, Drugs used in Diabetes, Vitamins-Minerals \& Food supplements, Local/General Anesthetics, solutions correcting water \& electrolyte disturbances and Vaccine. PMBJAP provides self employment and income opportunity to registered pharmacist with valid license and 10 square meter space anywhere in the country. The application to open PMBK is available on the website www.janaushadhi.gov.in [4]. 
Department of Pharmaceuticals Ministry of Chemicals \& Fertilizers Government of India

Shastri Bhawan, New Delhi-110001

Website: pharmaceuticals.gov.in
Bureau of Pharma PSUs of India (BPPI)

IDPL Corporate Office Complex

Old Delhi-Gurugram Road

Dundahera, Gurugram - 122016 (Haryana)

Website: janaushadhi.gov.in

Figure 3 Address \& Websites of Department of Pharmaceuticals and Bureau of Pharma PSUs of India (BPPI). PMJAK functions under PMBJP, PMBJP is under control of BPPI and BPPI is started by department of Pharmaceuticals,

Ministry of Chemicals \& Fertilizers, Government of India

Number of PMBJK differs from state to state and from UTs to UTs because of area and population. The distribution of PMBJK in different States \& Union Territories are as follows : Andaman \& Nicobar (1), Andhra Pradesh (178), Arunachal Pradesh (28), Assam (77), Bihar (222), Chandigarh (7), Chhattisgarh (229), Delhi (291), Goa (9), Gujarat (508), Haryana (200), Himachal Pradesh (58), Jammu And Kashmir (90), Jharkhand (70), Karnataka (868), Kerala (744), Ladakh (3), Lakshadweep (Medicines are directly supplied to the administration of UT) (0), Madhya Pradesh (216), Maharashtra (566), Manipur (32), Meghalaya (14), Mizoram (22), Nagaland (15), Odisha (267), Puducherry (16),Punjab (275), Rajasthan (114), Sikkim (3), Tamil Nadu (773), Telangana (141), The Dadra And Nagar Haveli (31) and Daman \& Diu, Tripura (24), Uttar Pradesh (1058), Uttarakhand (201) and West Bengal (156). As per the latest update on www.janaushadhi.gov.in (06.08.2021), the total number of kendras are 8012 [3].

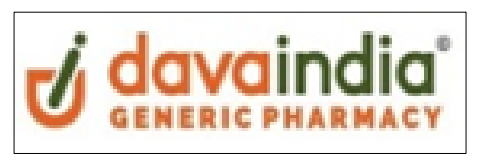

Figure 4 Logo of Davaindia, a popular name in non-government generic retail chain outlets functioning under Zota Healthcare

Davaindia is Generic Pharmacy chain in India with a wide range of Generic medicine. It is a unit of Zota Healthcare which was established in 1995 as a drug development, manufacturing and marketing company. The head office of Davaindia is located at Surat, Gujarat and more than 550 stores are functioning across 23 states of the country till 2020 [5].

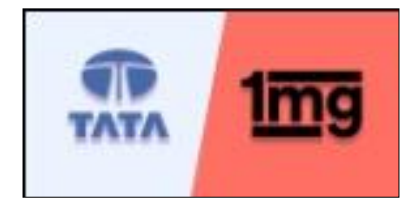

Figure 5 Logo of Tata $1 \mathrm{mg}$, a popular e-pharmacy gives facility to order medicines online and delivery at your door steps

$1 \mathrm{mg}$, now it is Tata $1 \mathrm{mg}$, is a e-pharmacy i.e. digital healthcare platform where one can order medicines (Allopathic, Ayurvedic \& Homeopathic) online from anywhere in the country and the medicines will be delivered at home [6].

\section{Conclusion}

In order to reduce the expenses on medicines, it's very necessary to promote research to find new generic medicines/life saving medicine/essential medicines to get rid from expensive branded medicines. It will be helpful to those people who have less purchasing power. As we all know and faced the financial problems arose due to COVID-19. These low cost generic medicines can make people to fight pandemic like situations in a better way because they can get it in affordable price. Secondly, price of some generic medicines are high, Government should take some steps to decrease it. It is also recommended that Government should also promote companies like Davaindia or others to increase their outlets not only in urban but in rural too. 


\section{Compliance with ethical standards}

\section{Acknowledgments}

I would like to deliver my sincere thanks to the authors of the articles mentioned in the reference, due to whom I succeeded in writing this article in a better and beneficial way.

\section{Disclosure of conflict of interest}

The Authors declares that there is no conflict of interest.

\section{References}

[1] Aggarwal B, Gurnani M. Branded versus Generic Medicines - Cost-Saving and Life-Saving : A Review of the Difference. 30August 2013.

[2] Agarwal G. 89 percent of all prescriptions dispensed with a generic drug - Generics True need of the hour. ETHealthWorld. April 21, 2021.

[3] Ministry of Health and Family Welfare, Government of India. Sale of Generic Drugs in the country.

[4] Pradhanmantri Bhartiya Janaushadhi Pariyojna. Therapeutic group wise list of products.

[5] Davaindia. About generic retail chain pharmacy.

[6] Tata 1mg. Price of Davaindia generic medicines and their branded versions.

\section{Author's Short biography}

Mr. Tapan Kumar Mahato, presently working as Assistant Professor in_Department of
Pharmaceutical Analysis, B.Pharmacy College Rampura (Kakanpur), Godhra, District
Panchmahal, Gujarat, India. His experience is 13 years (10 in teaching and 03 in research)
and area of research is herbal antiulcer drugs. 05 papers and 01 book chapter has been
published in his credit till date in various Journals/Book of national/international repute
and presented 08 papers orally/poster in various seminars/conferences.

